\title{
Prevalence and Associated Risk Factors of Sepsis among Neonates Admitted into Neonatal Intensive Care Units of Public Hospitals in Dhaka
}

\begin{abstract}
Zannatun Nyma ${ }^{1}$, Mahfuzur Rahman ${ }^{2}$, S M Mehedi Hasan ${ }^{3}$, Naym Uddin Roby ${ }^{4}$, Farhana Khanam ${ }^{2}$, Md Ehsanul Alam ${ }^{5}$, Mohammad Ali ${ }^{2}$

1. Epidemiology and Public Health, American International University Bangladesh, Dhaka, BGD 2. Epidemiology and Public Health, International Centre for Diarrhoeal Disease Research, Dhaka, BGD 3. Epidemiology and Public Health, United International University, Dhaka, BGD 4. Epidemiology and Public Health, North South University, Dhaka, BGD 5. Physical Medicine and Rehabilitation, Dhaka Medical College and Hospital, Dhaka, BGD
\end{abstract}

Corresponding author: Zannatun Nyma,dr.zannatun.nyma@gmail.com
Received 03/19/2020 Review began 03/21/2020 Review ended 03/26/2020 Published 03/29/2020

๑) Copyright 2020 Nyma et al. This is an open access article distributed under the terms of the Creative Commons Attribution License CC-BY 4.0., which permits unrestricted use, distribution, and reproduction in any medium, provided the original author and source are credited.

\begin{abstract}
Objective: To determine the prevalence and associated risk factors of sepsis among neonates admitted into neonatal intensive care units (NICU) of public hospitals in Dhaka.

Methods: This was a cross-sectional study conducted among 173 neonates admitted into the NICUs of Dhaka Medical College Hospital (DMCH) and Dhaka Shishu (Children) Hospital from March 1, 2016 to September 30, 2016 at Dhaka, Bangladesh. On the basis of the presence of clinical signs and symptoms of sepsis, neonates were admitted into the NICUs. The weight of the baby was measured and blood culture, complete blood count (CBC), C-reactive protein (CRP) and urine R/M/E were done at the time of admission. The neonates, who had positive blood culture reports, were confirmed as having sepsis. After receiving informed written consent, maternal data were collected from the mother of the neonate and neonatal data were collected from NICUs.
\end{abstract}

Results: The prevalence of sepsis among the neonates admitted into NICU of the concerned public hospitals in Dhaka was 69.35\%. In the multiple logistic regression model, perinatal asphyxia (adjusted odds ratio $(\mathrm{aOR})=3.37,95 \%$ confidence interval $(\mathrm{CI})=1.27-8.90)$, presence of infection at umbilical cord $(\mathrm{aOR}=3.32$, $95 \% \mathrm{CI}=1.40-7.85)$, history of bottle feeding of the neonates $(\mathrm{aOR}=3.02,95 \% \mathrm{CI}=1.11-8.25)$ and preexisting maternal infection $(\mathrm{aOR}=4.44,95 \% \mathrm{CI}=1.92-10.26)$ were significantly ( $\mathrm{p}$-value $<0.05)$ associated with neonatal sepsis. The odds of developing sepsis among the neonates with $\leqslant 2.5 \mathrm{~kg}$ weight at admission was more than three times higher $(\mathrm{aOR} 3.82,95 \% \mathrm{CI}=1.59-9.19)$ than neonates with admission weight $>2.5$ $\mathrm{kg}$.

Conclusion: Like other South Asian countries, the prevalence of neonatal sepsis is alarming in Bangladesh. Further research should be conducted to measure the burden of infections in the entire neonatal period and observe the effects of biological risk factors on the early and late-onset neonatal sepsis.

Categories: Pediatrics, Epidemiology/Public Health

Keywords: neonatal sepsis, prevalence, risk factors, bangladesh

\section{Introduction}

Over four million neonates die each year globally with the majority of the deaths occurring in low- and middle-income countries (LMICs) [1,2]. The estimated neonatal mortality rate in LMICs is 20 per 1000 live births, compared to three per 1000 in high-income countries [2]. These deaths have been categorically attributed to neonatal sepsis, meningitis, respiratory tract infections, diarrhoeal diseases, neonatal tetanus and prematurity which, in most cases, are preventable or treatable [3,4]. Previous studies revealed neonatal sepsis to be the most common cause of neonatal mortality $[5,6]$.

Neonatal sepsis, a systemic infection precipitating within the first 28 days after birth, encompasses bloodstream infection, meningitis, and pneumonia [7]. It currently is responsible for about 1.6 million annual deaths among neonates worldwide, $99 \%$ of which take place in developing countries $[8,9]$. Of the total sepsis-related neonatal deaths in 2013, 38.9\% occurred in South Asia alone [7]. Epidemiological estimates suggested that the global prevalence of neonatal sepsis was 1.7 million in 2010 [10]. South Asia and subSaharan African countries share the highest-burden of neonatal sepsis cases in the world; Bangladesh, being a developing South Asian country, is not an exception to this very trend [7,11].

Neonatal sepsis is a high-priority public health issue, particularly in the context of a developing country, where it constantly emerges as one of the major contributors to neonatal morbidity and mortality [12]. In addition to the substantial percentage of immediate mortality, neonatal sepsis imposes a wide range and 
varying degrees of long-term disabilities upon the survivors in their future [13]. Previous research revealed that such long-term impairments might be in the form of cognitive disability, learning disabilities, developmental delays, hearing loss or visual disturbance, resulting in a major socio-economic burden in resource-poor countries and contributing to the global disease burden [14,15]. The global burden of morbidity was estimated at about 3\% of all Disability Adjusted Life Years (DALYs) [16]. Moreover, neonatal sepsis leads to the causes of neonatal hospital admissions in developing countries [17].

Some studies conducted in Bangladesh focused only on the bacteriological profile and antimicrobial susceptibility regarding neonatal sepsis [18-20]. As neonatal sepsis encompasses a number of diseases that are preventable, along with lab-based study for causative organisms, it is crucial to identify the risk factors related to it [21]. Depending on the variation of the study population, marked divergence concerning risk factors of neonatal sepsis has been reported [12]. In Bangladesh, only very few studies attempted to determine the risk factors of neonatal sepsis [22-23]. The overall lack of data on neonatal sepsis in Bangladesh spurred this research to identify risk factors influencing neonatal sepsis so that appropriate intervention measures and resource mobilization can be initiated for addressing the modifiable risk factors. Identification of the risk factors associated with neonatal sepsis could also provide significant insights leading to new findings for neonatal sepsis prevention, early diagnosis, and better treatment, thereby reducing morbidity and mortality.

Considering all these contexts, we carried out a cross-sectional study to determine the prevalence and associated risk factors of sepsis among neonates admitted into neonatal intensive care units (NICU) of public hospitals in Dhaka.

\section{Materials And Methods}

We conducted an institution based cross-sectional study in the NICUs of Dhaka Medical College Hospital (DMCH) and Dhaka Shishu (Children) Hospital. The study was undertaken from March 1, 2016 to September 30, 2016 and included 173 neonates admitted in the NICUs of these two hospitals during the study period.

The NICUs of DMCH and Dhaka Shishu (Children) Hospital had the capacity to treat 36 and 14 neonates respectively at a time during the study period. The weight of the baby was measured at the time of admission. In suspected neonatal sepsis cases, physicians admitted the neonates into the NICUs of the hospitals on the basis of the presence of clinical signs and symptoms of neonatal sepsis [24]. Blood culture, complete blood count (CBC), C-reactive protein (CRP) and urine R/M/E were done at the time of admission. The neonates, who had positive blood culture reports, were confirmed as having sepsis. Inclusion criteria were - all neonates (0-28 days) admitted in the particular NICUs during the study period and whose mothers gave informed consent to include her baby in our study. Exclusion criteria included - any case of neonatal death taking place in the concerned ICUs during the data collection period and neonates whose mothers refused to give informed consent.

A standard semi-structured questionnaire was used to collect neonatal and maternal data. Before data collection, the mother of a neonate was given a detailed explanation of the study. After receiving informed written consent, maternal data were collected from the mother of the neonate which included sociodemographic conditions, location of delivery, maternal health conditions. Neonatal data were collected from NICUs which included admission weight of the baby, presence of neonatal sepsis, the gender of the baby, TORCH infection (toxoplasmosis, others - syphilis, rubella, cytomegalovirus, and herpes simplex viral infection), perinatal asphyxia, fetal malformation, cord care of the neonate, history of bottle feeding and pre-lacteal feeding. The presence of neonatal sepsis was the outcome variable. Neonatal sepsis and perinatal asphyxia were defined as follows:

Neonatal sepsis was defined as a systemic infection occurring in the first 28 days of life that encompassed blood-stream infection, meningitis and pneumonia occurring among the neonates evidenced by positive blood culture report [7].

Perinatal asphyxia is a clinical condition that results from the impaired gas exchange in the fetus. This leads to hypoxia, hypercarbia, and acidosis and these ultimately culminate in failure to establish and sustain spontaneous respiration immediately after birth [24].

After gathering all the required information, data was compiled, analyzed and tabulated in accordance with key variables. Data analysis was performed on the basis of the research question and the objective. The statistical software package Stata, version 14.0 (LP StataCorp, College Station, TX) was used to analyze the data. Descriptive statistics were calculated for all the variables, including mean, standard deviation, frequencies, and percentages. In order to assess the association between the outcome variable (neonatal sepsis) and independent variables, at first, we performed a simple logistic regression analysis (Chi-square test). The variables that were found statistically significant (having p-value $\leqslant 0.25$ ) at the simple logistic regression model, we kept them in a multiple logistic regression model. The results of the multiple logistic regression model were presented in terms of the adjusted odds ratio (aOR) with respective $95 \%$ confidence interval (CI). 


\section{Cureus}

Ethical approval for our study protocol was obtained from the Ethical Review Committee of the American International University Bangladesh (AIUB). Permission for collecting data was taken from the authority of DMCH and Dhaka Shishu (Children) Hospital.

\section{Results}

A total of 173 neonates were included in our study, of which 69.36\% (120 neonates) had been suffering from neonatal sepsis (Figure 1). Admission weight of 124 neonates was $\leqslant 2.5 \mathrm{~kg}$ and mean admission weight was 1.28 (standard deviation $(\mathrm{SD})=0.45$ ). Fifty-eight percent of neonates were male and $79.77 \%$ had been suffering from perinatal asphyxia. Sixty-six percent of neonates represented the presence of infection at the umbilical cord.

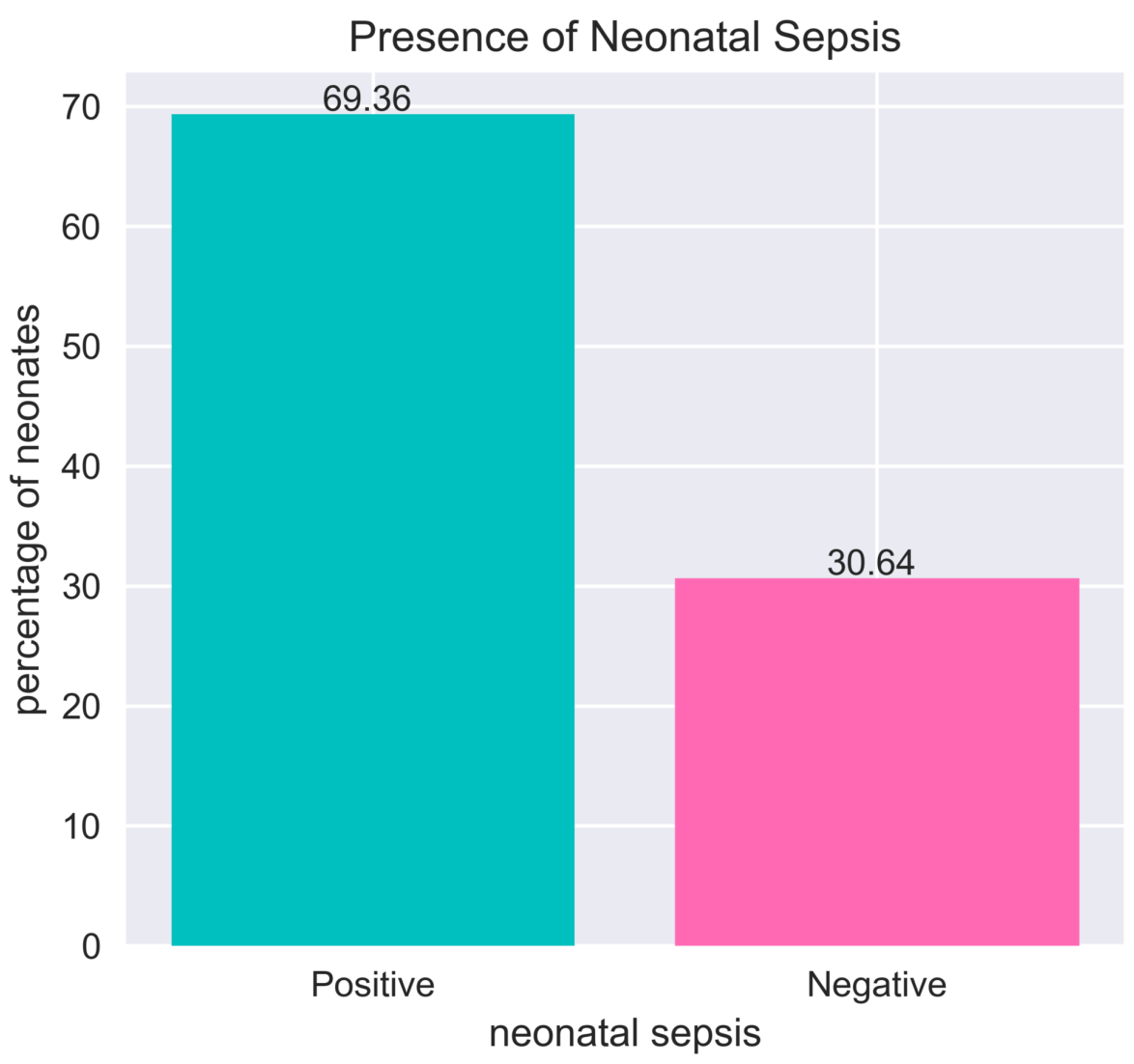

FIGURE 1: Presence of neonatal sepsis

The mean age of the mothers of the neonates was 24.81 ( $\mathrm{SD}=5.47)$ and mean age at the marriage of them was 19.93 (SD=3.27). Fifty-five percent of mothers did not complete secondary school certificate (SSC) level and $67.63 \%$ of them were unemployed. Among 173 mothers, 63 had a history of single unclear or $>3$ sterile vaginal examinations during labor. Fifty-five percent of mothers had pre-existing maternal infections (TORCH infection/ hepatitis B, hepatitis C/ hepatitis E/ gonorrhea/chlamydia). Among 173 mothers, 135 had the history of co-morbidities state (pre-eclampsia/ diabetes/ urinary tract infection (UTI)/ pneumonia/maternal peripartum fever) (Table 1).

Variables

Values

Maternal Characteristics

Age in years (mean $\pm S D$ )

$24.81 \pm 5.47$

Age at marriage in years (mean $\pm S D$ )

$19.93 \pm 3.27$

Academic qualification $(\%, \mathrm{~N})$

$\leq \mathrm{SSC}$ Level

$55.49(96)$

Occupational status $(\%, \mathrm{~N})$ 


\section{Cureus}

Variablelnemployed

Family income (Per month) $(\%, \mathrm{~N})$

$\leq 15000$

Location of delivery $(\%, N)$

Hospital

83.24 (144)

Home

$15.61(27)$

Others (on the way to hospital, on footpath-police case)

$1.16(2)$

$39.31(68)$

Premature rupture of membrane (PROM) $(\%, N)$

$26.59(46)$

Anti-partum haemorrhage (APH) $(\%, N)$

$45.09(78)$

Multiple order of pregnancy $(\%, N)$

Single unclear or $>3$ sterile vaginal examinations during labor $(\%, N)$

Yes

$36.42(63)$

No

$46.82(81)$

Not Sure

$16.76(29)$

Pre-existing maternal infection $(\%, \mathrm{~N})$

Yes

$54.91(95)$

No

$45.09(78)$

Co-morbid states $(\%, \mathrm{~N})$

Yes

78.03 (135)

No

$21.97(38)$

Anemia (\%, N)

$<11.0 \mathrm{~g} / \mathrm{dlor} 6.8 \mathrm{mmol} / \mathrm{L}$

$62.43(108)$

Neonatal Characteristics

Admission weight $(\%, \mathrm{~N})$

$\leq 2.5 \mathrm{~kg}$

71.68 (124)

$>2.5 \mathrm{~kg}$

$28.32(49)$

Gender (\%, N)

Male

$57.8(100)$

Female

$42.2(73)$

Perinatal Asphyxia $(\%, \mathrm{~N})$

Present

79.77 (138)

Absent

Presence of infection at umbilical cord $(\%, \mathrm{~N})$

Yes

65.32 (113)

No

$34.68(60)$

History of bottle feeding $(\%, \mathrm{~N})$

$34.1(59)$

History of pre-lacteal feeding $(\%, \mathrm{~N})$

$14.45(25)$

\section{TABLE 1: Study population characteristics}




\section{Cureus}

SSC: Secondary school certificate; SD: standard deviation.

We presented the association of neonatal sepsis with different independent variables such as admission weight, gender, perinatal asphyxia, cord care, history of bottle feeding of the neonates, pre-existing maternal infection, co-morbid states, UTI, anemia and single unclear or $>3$ sterile vaginal examinations during labor in bivariate analysis (Table 2).

\begin{tabular}{|c|c|c|c|c|}
\hline \multirow[t]{2}{*}{ Variable label } & \multirow[t]{2}{*}{ Category } & \multicolumn{2}{|c|}{ Neonatal sepsis } & \multirow[t]{2}{*}{ p-value } \\
\hline & & Present $(\%, \mathrm{n})$ & Absent $(\%, n)$ & \\
\hline \multicolumn{5}{|l|}{ Maternal Characteristics } \\
\hline \multirow{2}{*}{ Single unclear or $>3$ sterile vaginal examinations during labor } & Yes & $79.37(50)$ & $20.63(13)$ & \multirow{2}{*}{0.031} \\
\hline & No & $63.64(70)$ & $36.36(40)$ & \\
\hline \multirow{2}{*}{ Pre-existing maternal infection } & No & $52.56(41)$ & $47.44(37)$ & \multirow{2}{*}{$<0.001$} \\
\hline & Yes & 83.16 (79) & $16.84(16)$ & \\
\hline \multirow{2}{*}{ Co-morbid states } & No & $55.26(21)$ & $44.74(17)$ & \multirow{2}{*}{0.033} \\
\hline & Yes & 73.33 (99) & $26.67(36)$ & \\
\hline \multirow{2}{*}{ Urinary tract infection (UTI) } & No & $64.81(35)$ & 35.19 (19) & \multirow{2}{*}{0.068} \\
\hline & Yes & $79.01(64)$ & $20.99(17)$ & \\
\hline \multirow{2}{*}{ Anemia } & $<11.0 \mathrm{~g} / \mathrm{dlor} 6.8 \mathrm{mmol} / \mathrm{L}$ & $76.85(83)$ & $23.15(25)$ & \multirow{2}{*}{0.006} \\
\hline & $>11.0 \mathrm{~g} /$ dlor6.8mmol$/ \mathrm{L}$ & $56.92(37)$ & $43.08(28)$ & \\
\hline \multicolumn{5}{|l|}{ Child Characteristics } \\
\hline \multirow{2}{*}{ Admission weight } & $\leq 2.5 \mathrm{~kg}$ & $81.45(101)$ & $18.55(23)$ & \multirow{2}{*}{$<0.001$} \\
\hline & $>2.5 \mathrm{~kg}$ & $38.78(19)$ & $61.22(30)$ & \\
\hline \multirow{2}{*}{ Gender } & Male & 73 (73) & $27(27)$ & \multirow{2}{*}{0.225} \\
\hline & Female & $64.38(47)$ & $35.62(26)$ & \\
\hline \multirow{2}{*}{ Perinatal Asphyxia } & Yes & 76.81 (106) & $23.19(32)$ & \multirow{2}{*}{$<0.001$} \\
\hline & No & 40 (14) & $60(21)$ & \\
\hline \multirow{2}{*}{ Presence of infection at umbilical cord } & Yes & $83.19(94)$ & $16.81(19)$ & \multirow{2}{*}{$<0.001$} \\
\hline & No & $43.33(26)$ & $56.67(34)$ & \\
\hline \multirow{2}{*}{ History of bottle feeding } & Yes & $83.05(49)$ & $16.95(10)$ & \multirow{2}{*}{0.005} \\
\hline & No & $62.28(71)$ & $37.72(43)$ & \\
\hline
\end{tabular}

TABLE 2: Association between neonatal sepsis and independent variables (unadjusted)

In the multiple logistic regression model, admission weight, perinatal asphyxia, presence of infection at the umbilical cord, history of bottle feeding of the neonates and pre-existing maternal infection were significantly (p-value < 0.05) associated with neonatal sepsis (Table 3). 


\section{Cureus}

\begin{tabular}{|c|c|c|c|c|}
\hline Variable label & Category & Odds Ratio (adjusted) & p-value & $95 \% \mathrm{Cl}$ \\
\hline \multicolumn{5}{|l|}{ Maternal Characteristics } \\
\hline \multirow[t]{2}{*}{ Pre-existing maternal infection } & No & Reference & & \\
\hline & Yes & 4.44 & $<0.001$ & $(1.92,10.26)$ \\
\hline \multicolumn{5}{|l|}{ Child Characteristics } \\
\hline \multirow[t]{2}{*}{ Admission weight } & $>2.5 \mathrm{~kg}$ & Reference & & \\
\hline & $\leq 2.5 \mathrm{~kg}$ & 3.82 & 0.003 & $(1.59,9.19)$ \\
\hline \multirow[t]{2}{*}{ Perinatal Asphyxia } & No & Reference & & \\
\hline & Yes & 3.37 & 0.014 & $(1.27,8.90)$ \\
\hline \multirow[t]{2}{*}{ Presence of infection at umbilical cord } & No & Reference & & \\
\hline & Yes & 3.32 & 0.006 & $(1.40,7.85)$ \\
\hline \multirow[t]{2}{*}{ History of bottle feeding } & No & Reference & & \\
\hline & Yes & 3.02 & 0.031 & $(1.11,8.25)$ \\
\hline
\end{tabular}

TABLE 3: Association between neonatal sepsis and independent variables (adjusted)

The neonates whose mothers had the pre-existing infection had more than four $(\mathrm{aOR}=4.44,95 \% \mathrm{CI}=1.92$ 10.26) times higher chance of developing neonatal sepsis compared to the neonates whose mothers did not have pre-existing infections. The odds of developing sepsis among the neonates with $\leqslant 2.5 \mathrm{~kg}$ weight at admission was more than three times higher (aOR 3.82, CI: 1.59 to 9.19) than neonates with admission weight $>2.5 \mathrm{~kg}$. Neonates having perinatal asphyxia had 3.37 times (CI: 1.27 to 8.90 ) higher chance of developing neonatal sepsis compared to those who did not have this complaint/ diagnosis. Bottle-fed neonates had 3.02 times (CI: 1.11 to 8.25 ) higher chance of developing sepsis. The adjusted odds of developing neonatal sepsis among children with umbilical cord infection were 3.32 times higher compared to neonates without cord infection.

\section{Discussion}

This study illustrates the prevalence of neonatal sepsis which is one of the prime causes of hospitalization for neonates in developing countries [25-26]. This study also revealed the association of risk factors with sepsis after the hospitalization of neonates. We categorized maternal and neonatal factors to see their relationship with sepsis. Maternal factors mainly include urinary tract infection, pre-existing maternal infection and anemia while neonatal factors include admission weight, perinatal asphyxia, presence of infection at umbilical cord and history of bottle feeding of the neonates.

Our study found a high prevalence of neonatal sepsis (69.36\%) in NICU admitted patients. Another study at Chittagong Medical College Hospital, Bangladesh had almost the same findings of early-onset neonatal sepsis (65.38\%) and late-onset neonatal sepsis (34.62\%) [18]. Although the findings appeared similar, the study from Motara et al. showed about $5 \%$ early-onset and $91 \%$ late-onset neonatal sepsis [25]. In Indian studies, the prevalence of neonatal sepsis was found $23.3 \%$ in Bihar which was lower than other cities like Delhi $[26,27]$. This could be due to the higher socio-demographic, economic or education level. A community-based study proved a higher incidence (14.5\%) of sepsis in neonates in Bangladesh [28].

In this study, we found that the mothers' educational level below secondary level had a higher effect in neonatal sepsis which is similar to another study from Saqeeb et al. [29]. Several risk factors are associated with early and late-onset of neonatal sepsis and low birth weight was found highly significant [27-29]. We found that almost $81.5 \%$ of patients in NICU were suffering from sepsis and their admission weight was $2.5 \mathrm{~kg}$. Some studies indicated, perinatal asphyxia as one of the major reasons for developing sepsis in neonates, and this is similar to our study [12,27,29]. The study from Mitra et al. found that uncleaned cord care had a significant effect on developing sepsis in neonates [28]. In our observation, there was a higher proportion of umbilical cord infection which supports other studies.

Some other factors like history of bottle feeding of the neonates, pre-existing maternal infection were also found responsible for developing sepsis in neonates. Though UTI had a significant association with developing neonatal sepsis, our research did not find any significance [30]. There should be further prospective research implemented with a larger sample size to observe the effects of biological risk factors 
on early- and late-onset neonatal sepsis.

Turning to our limitations, some biologically significant variables related to maternal characteristics such as academic qualification, area of residence, premature rupture of membrane (PROM), history of co-morbid state (pre-eclampsia, gestational diabetes mellitus, UTI, pneumonia) and anemia were represented as statistically insignificant because of the small sample size (173 neonates) in our study. Moreover, we could not follow the neonates from birth ( $16 \%$ of mothers participated in our study had history of home delivery and $1.16 \%$ had history of delivery on the way to hospital and footpath), so we were unable to take birth weight of the neonates.

\section{Conclusions}

The prevalence of neonatal sepsis among the neonates admitted at NICU in Bangladeshi public hospitals is higher. Major determinants of neonatal sepsis are pre-existing maternal infection, weight of the baby, perinatal asphyxia, and presence of infection at the umbilical cord of the neonate. Therefore, we recommend interventions at three stages - during pregnancy, during delivery, and during neonatal period in order to address the problem of neonatal sepsis. However, further studies are needed to be conducted with large sample size to strengthen our observation.

\section{Additional Information \\ Disclosures}

Human subjects: Consent was obtained by all participants in this study. Ethical Review Committee issued approval 15-98437-1. This is to certify that Dr. Zannatun Nyma (ID \# 15-98437-1) enrolled at the Masters in Public Health (MPH) Program under the Department of Public Health in the American International University-Bangladesh, (AIUB). She has presented a research proposal on April 02, 2016 entitled "Risk assessment of Neonatal Sepsis among Low Birth Weight Babies in Public and Private Hospitals in Bangladesh" to the Research Review Committee (RRC) and Ethical Review Committee (ERC) under the Department of Public Health. Both the Committees examined the research proposal carefully and approved for undertaking research work for the completion of dissertation which is a prerequisite for obtaining the degree of MPH form AIUB. The Ethical Review Committee (ERC) examined the scientific and social implications of the research proposal and ethical aspects of research involving human subjects under social context. The elements the committee examined included the justification of research, moral imperatives, ethical principles and the laws. The Proposal fulfills two essential components: A. The selection and achievement of morally acceptable ends and B. The morally acceptable means to means to those ends Guiding ethical principles express common standards, values and aspirations which the researchers promised to follow during different phases of the study. They are as follows: 1. Respect for human dignity. 2. Respect for free and informed consent. 3. Respect for vulnerable persons. 4. Respect for privacy and confidentiality. 5. Respect for justice and inclusiveness. 6. Balancing harms and benefits. 7. Minimizing harm and 8. Maximizing benefits. With the conditions mentioned above the RRC approved the above noted study which consists of the articulation of national norms that are applied through prospective ethics and review of research projects. Animal subjects: All authors have confirmed that this study did not involve animal subjects or tissue. Conflicts of interest: In compliance with the ICMJE uniform disclosure form, all authors declare the following: Payment/services info: All authors have declared that no financial support was received from any organization for the submitted work. Financial relationships: All authors have declared that they have no financial relationships at present or within the previous three years with any organizations that might have an interest in the submitted work. Other relationships: All authors have declared that there are no other relationships or activities that could appear to have influenced the submitted work.

\section{Acknowledgements}

The authors would like to express their earnest thanks to all the staff members of the neonatal intensive care units of Dhaka Medical College Hospital and Dhaka Shishu (Chindren) Hospital including physicians and nurses for their valuable support.

\section{References}

1. Knippenberg R, Lawn JE, Darmstadt GL, Begkoyian G, Fogstad H, Walelign N, Paul VK: Systematic scaling up of neonatal care in countries. Lancet. 2005, 365:1087-98. 10.1016/S0140-6736(05)71145-4

2. WHO: Joint child malnutrition estimates - levels and trends (2017 edition) . (2017). Accessed: May 29, 2019 : https://www.who.int/nutgrowthdb/estimates2016/en/.

3. Costello A, Francis V, Byrne A, Puddephatt C: State of the world's newborns: a report from saving newborn lives. ERIC Clearinghouse. 2001, 59. Accessed: February 14, 2020: https://files.eric.ed.gov/fulltext/ED458972.pdf.

4. Rakholia R, Rawat V, Bano M, Singh G: Neonatal morbidity and mortality of sick newborns admitted in a teaching hospital of Uttarakhand. CHRISMED J Health Res. 2014, 1:228-234. 10.4103/2348-3334.142983

5. Galhotra S, Gupta V, Bains HS, Chhina D: Clinico-bacteriological profile of neonatal septicemia in a tertiary care hospital. J Mahatma Gandhi Inst Med Sci. 2015, 20:148-152. 10.4103/0971-9903.164240

6. Baqui AH, El-Arifeen S, Darmstadt GL, et al.: Effect of community-based newborn-care intervention package 
implemented through two service-delivery strategies in Sylhet district, Bangladesh: a cluster-randomised controlled trial. Lancet. 2008, 371:1936-44. 10.1016/S0140-6736(08)60835-1

7. Naghavi M, Abajobir AA, Abbafati C, et al.: Global, regional, and national age-sex specific mortality for 264 causes of death, 1980-2016: a systematic analysis for the Global Burden of Disease Study 2016. Lancet. 2017, 390:1151-210. 10.1016/S0140-6736(17)32152-9

8. Softić I, Tahirović H, Di Ciommo V, Auriti C: Bacterial sepsis in neonates: single centre study in a neonatal intensive care unit in Bosnia and Herzegovina. Acta Medica Academica. 2017, 46:7-15. 10.5644/ama2006124.181

9. Black RE, Cousens S, Johnson HL, et al.: Global, regional, and national causes of child mortality in 2008: a systematic analysis. Lancet. 2010, 375:1969-87. 10.1016/S0140-6736(10)60549-1

10. Seale AC, Blencowe H, Zaidi A, et al.: Neonatal severe bacterial infection impairment estimates in South Asia, sub-Saharan Africa, and Latin America for 2010. Pediatr Res. 2013, 74:73-85. 10.1038/pr.2013.207

11. Liu L, Oza S, Hogan D, et al.: Global, regional, and national causes of child mortality in 2000-13, with projections to inform post-2015 priorities: an updated systematic analysis. Lancet. 2015, 385:430-440. 10.1016/S0140-6736(14)61698-6

12. Leal YA, Álvarez-Nemegyei J, Velázquez JR, Rosado-Quiab U, Diego-Rodríguez N, Paz-Baeza E, DávilaVelázquez J: Risk factors and prognosis for neonatal sepsis in southeastern Mexico: analysis of a four-year historic cohort follow-up. BMC Pregnancy Childbirth. 2012, 12:48. 10.1186/1471-2393-12-48

13. Stoll BJ, Hansen NI, Adams-Chapman I, Fanaroff AA, Hintz SR, Vohr B, Higgins RD: Neurodevelopmental and growth impairment among extremely low-birth-weight infants with neonatal infection. JAMA. 2004, 292:2357-65. 10.1001/jama.292.19.2357

14. Mwaniki MK, Atieno M, Lawn JE, Newton CR: Long-term neurodevelopmental outcomes after intrauterine and neonatal insults: a systematic review. Lancet. 2012, 379:445-452. 10.1016/S0140-6736(11)61577-8

15. World Health Organization and the World Bank: The Global Burden of Disease. Murray CJL, Lopez AD (ed): Harvard University Press, USA; 1996.

16. Murray CJ, Vos T, Lozano R, et al.: Disability-adjusted life years (DALYs) for 291 diseases and injuries in 21 regions, 1990-2010: a systematic analysis for the Global Burden of Disease Study 2010. Lancet. 2012, 380:2197-223. 10.1016/S0140-6736(12)61689-4

17. Softić I, Tahirović H, Di Ciommo V, Auriti C: Bacterial sepsis in neonates: single centre study in a Neonatal intensive care unit in Bosnia and Herzegovina. Acta Medica Academica. 2017, 46:7-15. 10.5644/ama2006124.181

18. Hafsa A, Fakruddin M, Hakim MA, Sharma JD: Neonatal bacteremia in a neonatal intensive care unit: analysis of causative organisms and antimicrobial susceptibility. Bangladesh J Med Sci. 2011, 10:187-194. 10.3329/bjms.v10i3.8363

19. Haque ME, Mahmud AS, Khan MS, Akhtar N, Uddin MS, Hakim MA: Frequency and characteristics of the neonatal sepsis infections caused by extended-spectrum beta-lactamase (ESBL) producing and nonproducing organisms in the Chittagong area of Bangladesh. J Bacteriol. 2015, 5:1-12. 10.3923/bj.2015.1.12

20. Chan GJ, Baqui AH, Modak JK, et al.: Early-onset neonatal sepsis in Dhaka, Bangladesh: risk associated with maternal bacterial colonisation and chorioamnionitis. Trop Med Int Health. 2013, 18:1057-64. 10.1111/tmi.12150

21. Jehan I, Harris H, Salat S, et al.: Neonatal mortality, risk factors and causes: a prospective population-based cohort study in urban Pakistan. Bull World Health Organ. 2009, 87:130-138. 10.2471/BLT.08.050963

22. Rosenberg RE, Ahmed AN, Saha SK, et al.: Nosocomial sepsis risk score for preterm infants in low-resource settings. J Trop Pediatr. 2009, 56:82-89. 10.1093/tropej/fmp061

23. Darmstadt GL, Saha SK, Choi Y, et al.: Population-based incidence and etiology of community-acquired neonatal bacteremia in Mirzapur, Bangladesh: an observational study. Int J Infect Dis. 2009, 200:906-915. 10.1086/605473

24. Mollah MAH, Nahar N: Step on to Paediatrics (4th edition). Syeda Amena Meher, Dhaka; 2017.

25. Motara F, Ballot DE, Perovic O: Epidemiology of neonatal sepsis at Johannesburg hospital . South Afr J Epidemiol Infect. 2005, 20:90-93. 10.1080/10158782.2005.11441243

26. Kumar MK, Thakur SN, Singh BB: Study of the morbidity and the mortality patterns in the neonatal intensive care unit at a tertiary care teaching hospital in Rohtas district, Bihar, India. J Clin Diagnostic Res. 2012, 6:282-285. Accessed: February 10, 2020: https://jcdr.net/article_fulltext.asp?issn=0973709x \&year=2012 \&volume=6 \&issue=2 \&page=282 \&issn=0973-709x \&id=1994.

27. Jajoo M, Kapoor K, Garg LK, Manchanda V, Mittal SK: To study the incidence and risk factors of early onset neonatal sepsis in an out born neonatal intensive care unit of India. J Clin Neonatol. 2015, 4:91-95. 10.4103/2249-4847.154106

28. Mitra DK, Mullany LC, Harrison M, et al.: Incidence and risk factors of neonatal infections in a rural Bangladeshi population: a community-based prospective study. J Health Popul Nutr. 2018, 37:6. 10.1186/s41043-018-0136-2

29. Saqeeb KN, Hasan SMT, Khan A, Ahmed T, Chisti MJ: Determinants and outcome of community-acquired late-onset neonatal sepsis in rural Bangladesh. Glob Pediatr Heal. 2019, 6:1-8. 10.1177/2333794X19833730

30. Gebremedhin D, Berhe H, Gebrekirstos K: Risk factors for neonatal sepsis in public hospitals of Mekelle city, North Ethiopia, 2015: unmatched case control study. PLoS One. 2016, 11: e0154798.

10.1371/journal.pone.0154798 